\title{
The influence of process parameters on the properties of hot compacted self-reinforced polypropylene composites
}

\author{
Yentl Swolfs*1, Qingcheng Zhang ${ }^{1}$, Joris Baets ${ }^{1}$, Ignaas Verpoest ${ }^{1}$ \\ ${ }^{1}$ Department of Materials Engineering, KU Leuven, Kasteelpark Arenberg 44 bus 2450 , \\ Belgium \\ *Corresponding author: Yentl Swolfs (yentl.swolfs@mtm.kuleuven.be), Tel.: 003216 \\ 373616
}

\begin{abstract}
Hot compacted self-reinforced polypropylene composites have good tensile properties and excellent impact resistance, but they have a limited processing window. Therefore, the influence of compaction temperature, dwell time and the application of interleaved films on the tensile and impact properties was assessed. Increased compaction temperature allows more molecular relaxation, thereby melting more matrix and creating a stronger interlayer bonding. This results in reduced $0^{\circ}$ tensile properties and penetration impact resistance, while the $45^{\circ}$ tensile properties and non-penetration impact resistance are maintained or improved. The dwell time only has minor influences on tensile and impact properties, while interleaved films have a similar influence as increased compaction temperature. These films increase the interlayer bonding, which increases the tensile strength and non-penetration impact resistance, but reduces penetration impact resistance. This paper demonstrates a wide property range depending on the processing parameters, helping in future tailoring of self-reinforced composites to specific applications.
\end{abstract}

Keywords: A. Polymer-matrix composites (PMCs); B. Impact behaviour; B. Mechanical properties; Self-reinforced composites

\section{Introduction}

Polymers are increasingly replacing traditional materials such as wood, ceramics and metals. Their relatively low stiffness and strength hampers their applicability to compete in many applications. These properties can be improved by reinforcement fibres, such as carbon and glass fibres. The interface strength between the fibre and polymer, however, is a traditional problem. An elegant solution was proposed by Capiati and Porter [1], who invented the first self-reinforced composite, also referred to as single polymer composites or all-polymer composites. The reinforcing phase, which is an oriented polymer fibre or tape, is combined with an unoriented matrix phase from the same polymer. The molecular orientation of the reinforcing phase imparts excellent mechanical properties to these self-reinforced composites.

Several processes have been invented to create self-reinforced composites. Capiati and Porter's initial process [1] stacked films of low molecular weight PE in between the layers of high molecular weight PE fibres. The difference in melting point and orientation of both PE grades was exploited to create the first self-reinforced 
composites. In 1993, Hine et al. [2] reported a new approach, which starts off from an oriented homopolymer fibre. Their process, called hot compaction, exploits the difference in melting temperature between the outer sheath and the inner core of the fibre. This process has a narrow, yet viable temperature window. An alternative process is co-extrusion, developed by Peijs and co-workers [3-6]. This process uses bicomponent tapes, in which the outer layer is a lower-melting point copolymer and the inner layer is a homopolymer. This increases the processing window from a few degrees [7-9] to a few tens of degrees Celsius [3]. The main advantage is that co-extrusion works at a lower temperature and can therefore maintain higher mechanical properties. Some other processes have also been investigated, such as injection moulding [10] and continuous extrusion [11], but have not yet led to commercial exploitation. The most successful self-reinforced polymer is polypropylene (PP), as it excels in impact performance and processability [12-15].

Self-reinforced PP composites have better tensile properties than isotropic polypropylene [12], but they are weaker and more compliant than traditional fibrereinforced composites. Therefore, most of the current applications exploit its excellent impact resistance [12]. Alcock et al. [5] demonstrated the influence of the processing conditions on the impact resistance of co-extruded self-reinforced PP. They established delamination, tape fracture, and tape debonding as the main energy absorbing mechanisms and proved that the penetration impact resistance decreased with increased compaction pressure or temperature. This is mainly the case at low compaction temperatures where insufficient surface welding occurs to achieve proper bonding. At higher compaction temperatures, the influence seems to level off. The decrease in penetration impact resistance with increased temperature was also confirmed by Barany et al. [16].

Further investigation into the effects on impact velocity and test temperature were performed by Alcock et al. [17]. Aurrekoetxea et al. [18] performed repeated impact tests and established an energy threshold below which no plastic deformation occurs. Swolfs et al. [19] proved that there is only a small influence of the weave architecture on the penetration impact resistance, while Abraham et al. [20] demonstrated the importance of the type of PP polymorph on the penetration impact resistance in selfreinforced PP.

The addition of interleaved films is another way to optimise the processing and mechanical properties of self-reinforced composites. While many studies have investigated interleaved films in traditional fibre-reinforced composites [21, 22], their main goal was to increase fracture toughness and damage resistance in carbon fibrereinforced composites. In contrast, the main goal of interleaved films in self-reinforced composites is to achieve wider processing window. These films also increases the peel strength and hence the interlayer bonding $[19,23,24]$ by creating more matrix in between the fabric layers in hot compacted self-reinforced PP composites. Unfortunately, these films are known to reduce the penetration impact resistance [19], but it is not clear whether this is valid at other compaction temperatures and dwell times. The influence of the interleaved films on non-penetration impact resistance is currently unknown. 
This study assesses the influence of the process parameters for hot compacted selfreinforced PP composites. This influence has already been investigated for co-extruded self-reinforced PP composites by Alcock et al. [5]. The hot compaction process is much more sensitive to the process parameters, making it even more important to understand those influences for hot compaction. Furthermore, the study of Alcock et al. used strain mapping to determine the degree of plastic deformation, which does not measure the damage after a non-penetration impact event. Instead, this study uses ultrasonic Cscans, which leads to a more direct measurement of the extent of the damage [25].

\section{Materials and methods}

\subsection{Materials}

Propex Fabrics GmbH provided balanced twill 2/2 PP tape weaves with an areal density of $130 \mathrm{~g} / \mathrm{m}^{2}$. These PP tapes had a stiffness of $6.9 \pm 1.2 \mathrm{GPa}$ and a strength of $589+24$ $\mathrm{MPa}$ [26]. The weaves were overfed, a feature which is discussed in detail in Swolfs et al. [19]. Propex Fabrics $\mathrm{GmbH}$ also provided $20 \mu \mathrm{m}$ thick films of the same homopolymer PP grade as the tapes. These films have melting temperature of $163^{\circ} \mathrm{C}$.

\subsection{Hot compaction}

The weave was cut into layers of $320 \times 320 \mathrm{~mm}$ under $0^{\circ}$ and $45^{\circ}$. The $45^{\circ}$ layers were used to produce samples for $45^{\circ}$ tensile tests. A total of eight weave layers were stacked on top of each other to obtain samples without interleaved films. In other layups, a single film was interleaved in between each of the weave layers.

This assembly was placed between two $1 \mathrm{~mm}$ thick aluminium cover plates, which was then inserted into a Fontijne LabPro400 press. This press was preheated to the correct temperature, within the range of $180-194^{\circ} \mathrm{C}$. A pressure of 39 bar was applied throughout the process. The assembly was held at the pre-set temperature for 2,5 or 15 min. After the dwell time, the assembly was cooled down to $40^{\circ} \mathrm{C}$ in $5 \mathrm{~min}$. Unless otherwise mentioned, the standard dwell time and compaction temperature were $5 \mathrm{~min}$ and $188^{\circ} \mathrm{C}$.

\subsection{Differential scanning calorimetry}

Differential scanning calorimetry (DSC) samples were cut from the middle of the hot compacted plates, as that location has the most reproducible temperature profile during hot compaction. The samples with a $2 \mathrm{mg}$ nominal weight were tested in a TA instruments Q2000. These low sample weights are needed to obtain accurate DSC measurements in self-reinforced composites. Despite the low sample weights, the DSC thermograms were reproducible, showing that the relative amount of tapes and matrix was similar in all cases.

The samples were heated from room temperature to $200^{\circ} \mathrm{C}$ at $10^{\circ} \mathrm{C} / \mathrm{min}$, with a constant flow of $50 \mathrm{ml} \mathrm{air} / \mathrm{min}$. At least four samples were tested for each configuration. The melting temperature was determined at the maximum of the heat capacity versus temperature. 


\subsection{Tensile tests}

Tensile tests were performed on an Instron 4505 tensile machine, with hydraulic clamps and a $100 \mathrm{kN}$ load cell. The load cell was electronically scaled to $10 \mathrm{kN}$ to improve its accuracy. The tensile samples measured 250 by $25 \mathrm{~mm}$ and were tested at a gauge length of $150 \mathrm{~mm}$, according to ASTM D3039. A minimum of 5 samples was tested for each processing condition. Sand paper was used in all cases to avoid slipping in the clamps. The strain was measured by digital image correlation of images of a speckle pattern on the sample surface, taken every $250 \mathrm{~ms}$. The modulus was calculated in the strain range $0.1-0.3 \%$. The strength was determined as the maximum stress in the tensile diagram and the corresponding strain is defined as the failure strain.

\subsection{Impact tests}

Two types of impact tests were performed: penetration and non-penetration. This terminology is used throughout, as it reflects more directly the difference between both types of impact than the terminology high and low energy impact. Falling weight impact tests were performed on a Fractovis CEAST 6789 machine, according to ISO 6603-2. In both cases, a hemispherical striker with $20 \mathrm{~mm}$ diameter was used to impact $100 \times 100 \mathrm{~mm}$ samples. All samples were clamped with a pressure of 9 bar and were tested at room temperature.

For the penetration impact tests, a $26.17 \mathrm{~kg}$ striker was dropped from $1 \mathrm{~m}$ height, resulting in an impact energy of 257J which was sufficient to cause penetration. These samples were clamped by a support ring with an inner and outer diameter of $40 \mathrm{~mm}$ and $60 \mathrm{~mm}$ respectively. The load was registered by a $20 \mathrm{kN}$ load cell in the striker tip, while the displacement was measured using a laser. Six samples were tested for each configuration. The penetration impact energy was calculated according to ISO 6603 as the area underneath the force-displacement diagram until the load has dropped below half of the peak load. This value was divided by the sample thickness.

For the non-penetration impact tests, a $3.17 \mathrm{~kg}$ striker was dropped from the same machine. The drop height was adjusted to achieve $5 \mathrm{~J}$ and $15 \mathrm{~J}$ impacts, both of which are energies high enough to induce damage but low enough to avoid penetration. The clamp had an inner and outer diameter of 80 and $100 \mathrm{~mm}$ respectively. This was deliberately chosen larger than for penetration impact tests to allow an easier assessment of the damaged area. Four samples were tested for each configuration.

\subsection{Ultrasonic C-scans}

The damaged area of the impacted samples was evaluated by ultrasonic pulse-echo Cscans in demineralised water. The scans were performed with an Olympus Panametrics V309SU transducer at a $5 \mathrm{MHz}$ frequency and $13 \mathrm{~mm}$ nominal diameter. The step size was $1 \mathrm{~mm}$. From the obtained grey scale values, the damaged area was calculated by setting the threshold to $70 \%$ of the maximum. The clamping also induced some damage into the samples, which was observed as a dark grey ring. To avoid the influence on the damaged area, only the area inside this ring was taken into account. This also avoided any influence from the weights and supports in the sample edges, which were needed to keep the sample at a fixed distance below the water surface. 


\section{Results}

\subsection{Thermal behaviour}

The drawn tapes typically have a very high crystallinity, while the degree of crystallinity is much lower in the films [27]. DSC was performed on hot compacted samples with and without films to analyse how the crystal structure is influenced by the hot compaction process. The DSC thermograms are plotted in Fig. 1, while the melting temperature and enthalpy values are summarised in Fig. 2.

With increased compaction temperature, the melting temperature increases by annealing of the crystals in the tapes during the compaction process. These crystals become closer to perfect and grow in size. The melting temperature of the tapes is not influenced by the presence of the interleaved films, as illustrated in Fig. 2a. The additional matrix has a lower melting temperature and appears either as a shoulder or as a small melting peak, right before the melting peak of the tapes. This shoulder or peak corresponds to the melting peak found in the thermogram of the films in Fig. 1b, and is less pronounced for samples without film. Some shoulders can be observed in samples without films due to the averaging of 4 thermograms. In the individual thermograms for samples without films, however, these shoulders are only present at a compaction temperatures of $191^{\circ} \mathrm{C}$ and $194^{\circ} \mathrm{C}$.

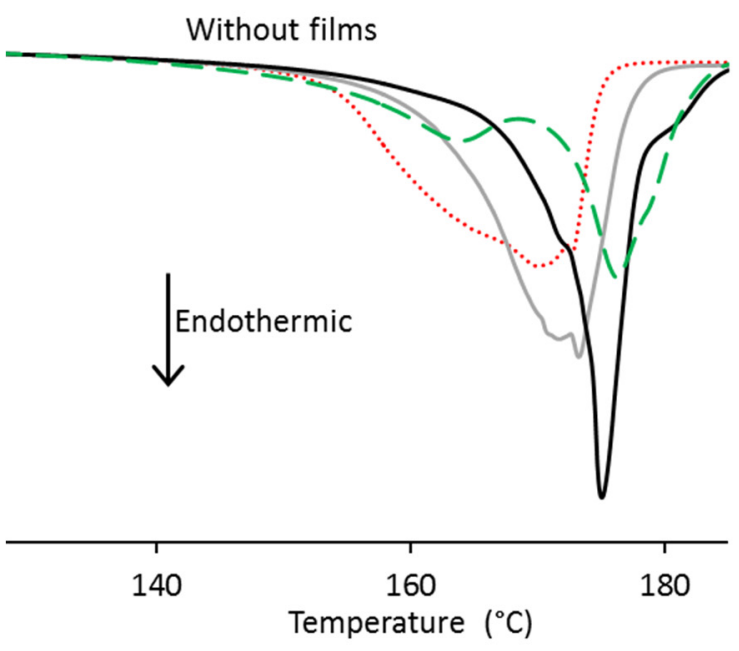

(a)

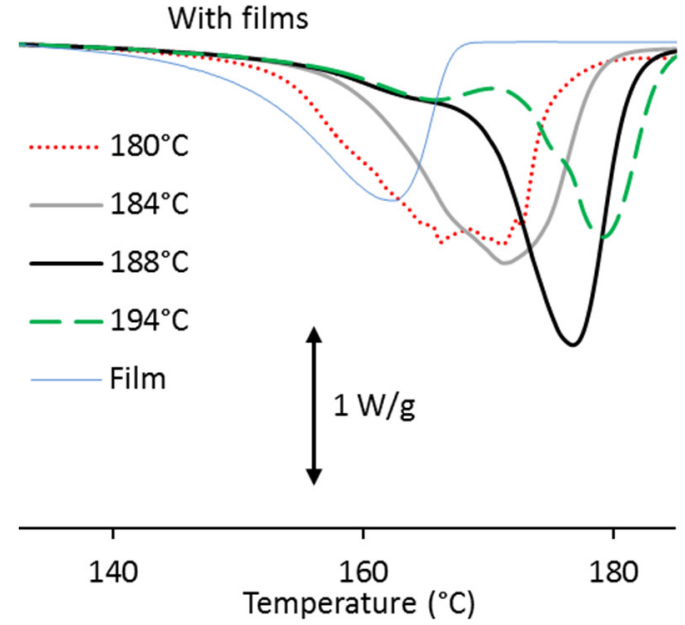

(b)

Figure 1: DSC thermograms for samples with a 5 minute dwell time: (a) without, and (b) with films. Each line represents the average of 4 DSC thermograms. The thermogram of the PP films is added as a reference, while the thermograms of $186^{\circ} \mathrm{C}$ and $191^{\circ} \mathrm{C}$ were omitted for clarity.

A larger difference is observed for the melting enthalpy in Fig. 2b. The samples with films have a lower melting enthalpy, as they contain less of the highly crystalline tapes. These tapes possess a higher melting enthalpy than the corresponding isotropic matrix $[28,29]$ and reduction in the volume fraction of tapes hence causes a decrease in the overall melting enthalpy. The decreasing trend with increasing compaction temperature is caused by melting of the tape surface, which creates matrix with a lower crystallinity. 

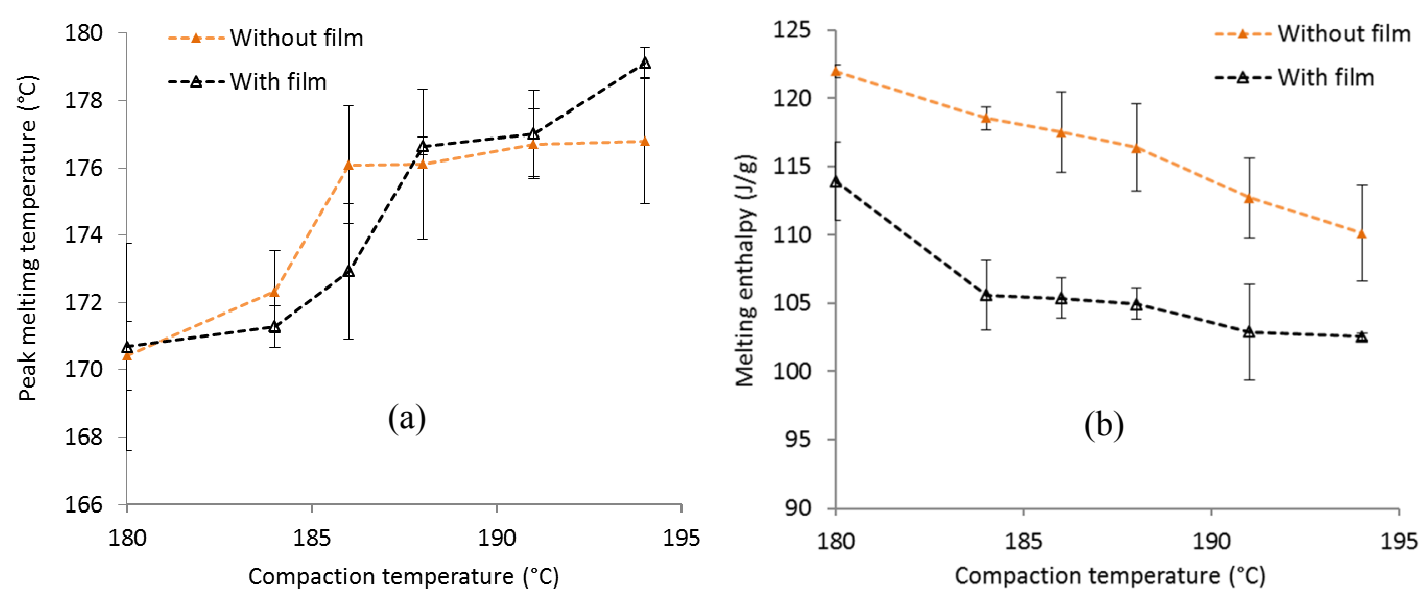

Figure 2: Differential scanning calorimetry results for samples with a 5 minute dwell time without and with films: (a) melting temperature, and (b) melting enthalpy.

The influence of dwell time on melting temperature and enthalpy is shown in Fig. 3. Dwell time does not have a clear influence on the melting temperature (see Fig. 3a). The melting enthalpy seems to be lowest at a dwell time of 5 min (see Fig. 3b), while it is higher for dwell times of 2 and $15 \mathrm{~min}$. The large scatter, combined with the small differences, indicates that DSC is not sensitive enough to make clear conclusions with respect to dwell time.
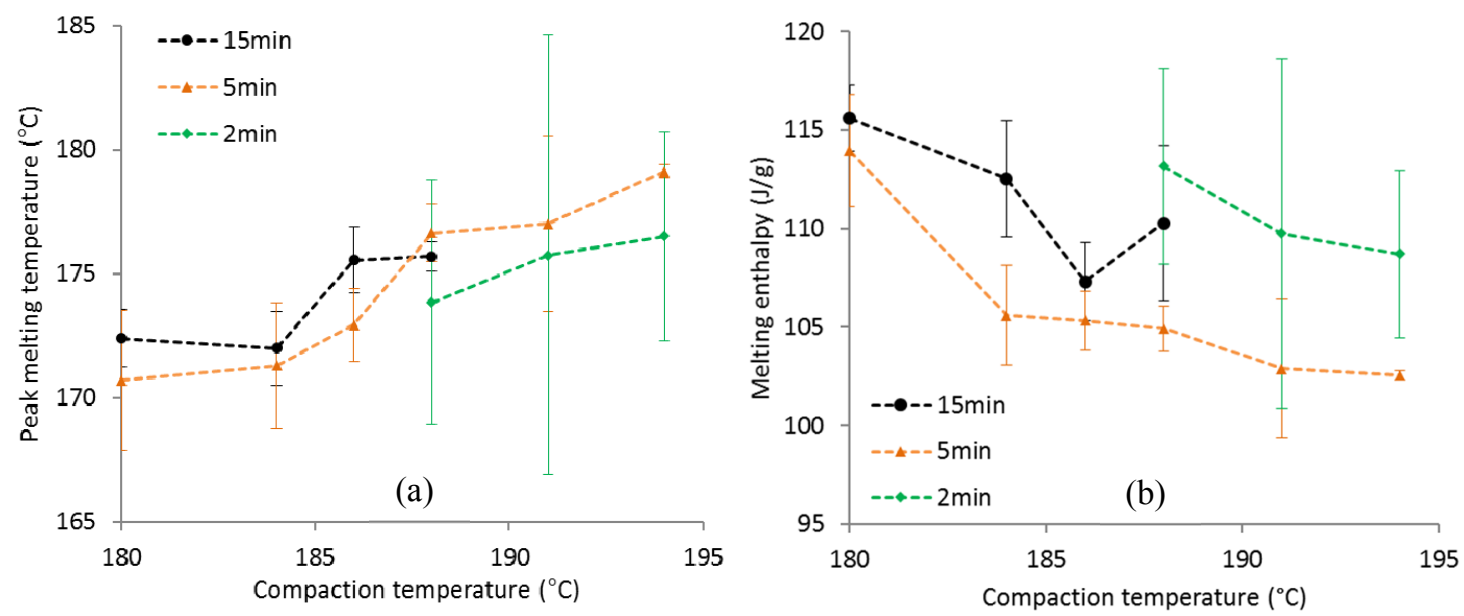

Figure 3: Influence of dwell time on differential scanning calorimetry results for samples with films: (a) melting temperature, and (b) melting enthalpy.

From the DSC results, it is clear that higher compaction temperature will have an important influence on the mechanical properties. This is a consequence of the increased molecular relaxation of the highly oriented crystalline structure in the tapes, and of the decreased tape fraction. The dwell time has a smaller influence and may not affect the mechanical properties.

\subsection{Tensile properties}

Fig. 4 summarises the $0^{\circ}$ tensile properties with and without interleaved films. For compaction temperatures above $180^{\circ} \mathrm{C}$, the tensile modulus is not affected by the films (see Fig. 4a). Firstly, the stiffness difference between matrix and tape is small compared to the difference in traditional fibre-reinforced composites. Secondly, the amount of 
additional matrix material is only $12 \%$, as the films are only $20 \mu \mathrm{m}$ thick. At a compaction temperature of $180^{\circ} \mathrm{C}$, however, the samples with films are significantly stiffer than the samples without films. This is caused by the poor compaction quality of the samples without films, as $5 \mathrm{~min}$ at $180^{\circ} \mathrm{C}$ melts insufficient matrix material to fill up all the voids in between the tapes and layers. In fibre-based self-reinforced composites, a matrix volume fraction of $20-30 \%$ is typically needed to fill all these voids and achieve proper interlayer bonding [30]. In tape-based self-reinforced composites, the optimal matrix volume fraction is most likely lower. In any case, the voids also contribute to the sample thickness, but do not affect the stress transfer in the $0^{\circ}$ direction, which results in a lower modulus.

A strongly decreasing modulus is observed if the compaction temperature is increased from $180^{\circ} \mathrm{C}$ to $186^{\circ} \mathrm{C}$ (see Fig. 4a). This can be attributed to two phenomena. Firstly, the amorphous, but oriented tie molecules between the crystals will relax [31]. Secondly, the volume fraction of tapes decreases with increased compaction temperature. At higher compaction temperatures, a small increase is observed, which might be attributed to the annealing effect on the matrix crystals. These crystals will grow in size and become more perfect [32], which can cause an increase in their tensile modulus. This annealing effect seems to be larger than the effect of increased molecular relaxation and decreased tape fraction.

Fig. $4 \mathrm{~b}$ proves that the tensile strength of samples with films is higher at low compaction temperatures than for samples without films, but that the difference decreases and disappears at higher compaction temperatures. The low interlayer bonding at low compaction temperatures causes early tape and interlayer debonding in the samples without films. These damage phenomena cause a less efficient load transfer between tapes or layers and thereby prevents the samples from reaching high strengths. The samples with films have better interlayer bonding, which results in clean and sudden failure, without much prior visible damage.

Fig. 4c plots the failure strain, which is calculated as the strain when the maximum stress is reached. The failure strain increases until $188^{\circ} \mathrm{C}$, after which a plateau is reached. Low compaction temperatures lead to low interlayer bonding, which causes early debonding and delamination. Also, molecular relaxation is more pronounced at high compaction temperatures. Both effects cause the failure strain to increase. Above $188^{\circ} \mathrm{C}$, the interlayer bonding is strong enough to prevent significant debonding, causing the failure strain increase to level off. Therefore, it seems that the interlayer bonding is more important for the failure strain than the molecular relaxation. 

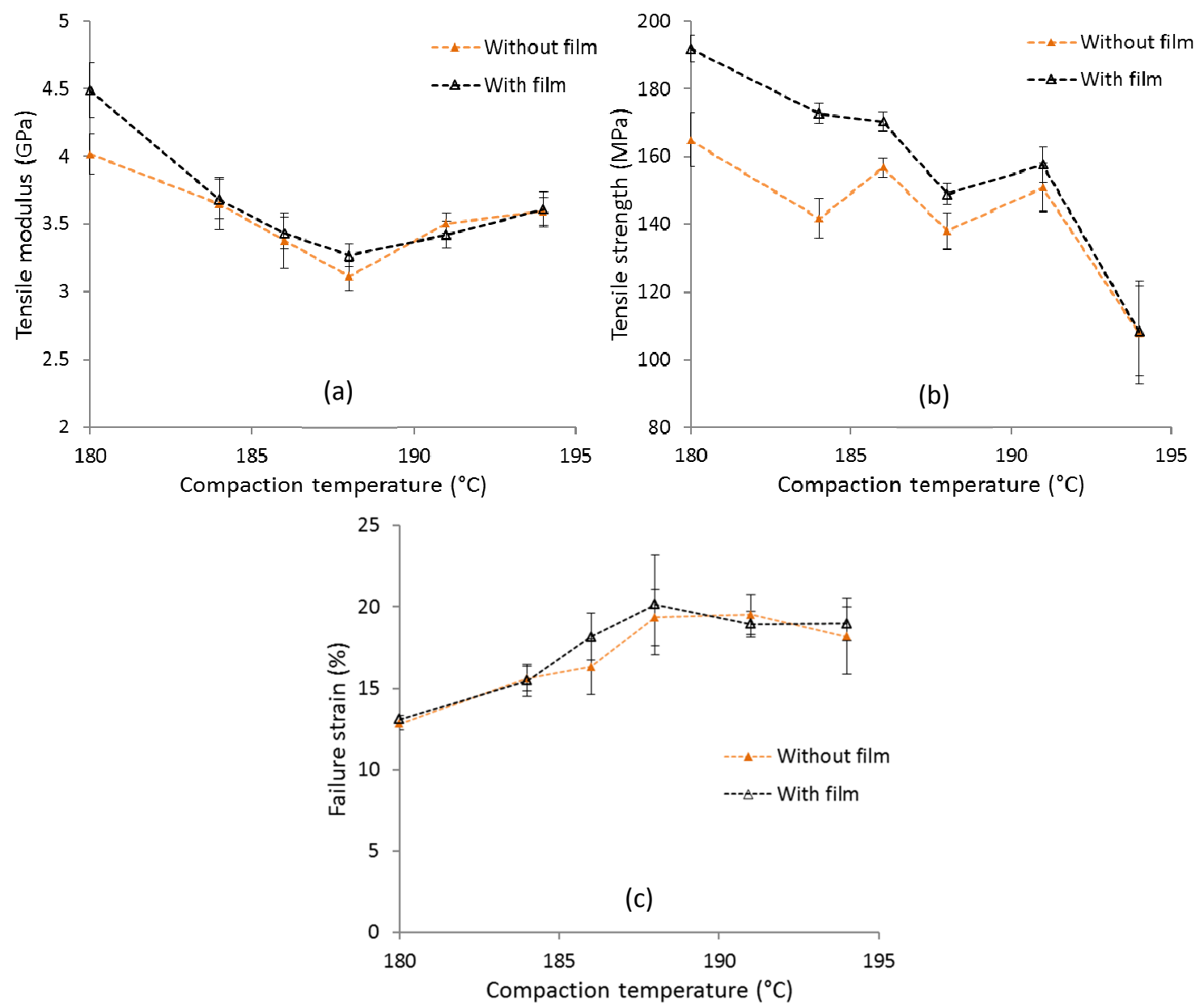

Figure 4: The $0^{\circ}$ tensile properties for samples without and with interleaved films at a dwell time of 5 min: (a) tensile modulus, (b) tensile strength, and (c) failure strain.

Tensile tests for different dwell times were performed in the $0^{\circ}$ and $45^{\circ}$ direction, and the results are summarised in Fig. 5. Fig. 5a demonstrates that the dwell time only has a small influence on the $0^{\circ}$ modulus. The $0^{\circ}$ modulus is lower when the dwell time is increased to $15 \mathrm{~min}$, allowing more molecular relaxation and reducing the tape fraction. The $45^{\circ}$ modulus is mainly dominated by the matrix, causing it to be hardly affected by compaction temperature and dwell time. Based on the increased modulus for higher compaction temperatures in Fig. 4a, which was explained based on increased matrix stiffness, it could be expected that the $45^{\circ}$ modulus should also be higher in Fig. $5 \mathrm{a}$. This increase is, however, only observed in the $0^{\circ}$ modulus. It could be hypothesised that some additional crystallinity is created in the tapes. The melting temperature of the tapes is indeed further increased at high compaction temperatures, but at the same time the melting enthalpy is reduced. In conclusion, there is insufficient evidence to explain the increases observed in Fig. 4a and 5a.

The results for tensile strength are shown in Fig. 5b. The $0^{\circ}$ tensile strength displays a strong decrease with increased compaction temperature, as the oriented tape fraction is reduced and loses some of its orientation. The $45^{\circ}$ tensile strength increases with decreased tape fraction, as more matrix is created. This matrix bonds the layers and tapes together, so they can shear over each other. At $180^{\circ} \mathrm{C}$, the tapes are poorly bonded and the in-plane shear stresses rapidly tear the tapes apart, as their length in the tensile 
samples is limited to only $35 \mathrm{~mm}$. With the increased bonding at higher temperatures, the tapes are able to reorient themselves in the tensile direction without causing shear failure between the tapes, and can thereby fully exploit the tensile strength of the tapes. At $194^{\circ} \mathrm{C}$, both diagrams seem to converge, meaning that the strength of the selfreinforced PP composites is becoming more isotropic. Longer dwell time tends to slightly reduce the $0^{\circ}$ tensile strength, although this reduction is small and not clear at all compaction temperatures. This confirms the DSC conclusions, which stated that dwell time has only a small influence on the relaxation, melting and recrystallization of self-reinforced PP composites.

The failure strain results in Fig. 5c confirm the previous conclusions. Longer dwell times create more matrix and hence better interlayer bonding. This stronger bonding can delay the onset of debonding during the tensile test and hence increase the failure strain. Simultaneously, longer dwell time also allows more molecular relaxation, which contributes to the increased failure strain with increased dwell time. Nevertheless, the influence of dwell time is relatively small in the $0^{\circ}$ direction. The effects in the $45^{\circ}$ direction are similar but more pronounced. This direction is more sensitive to the interlayer bonding and hence to the amount of matrix.
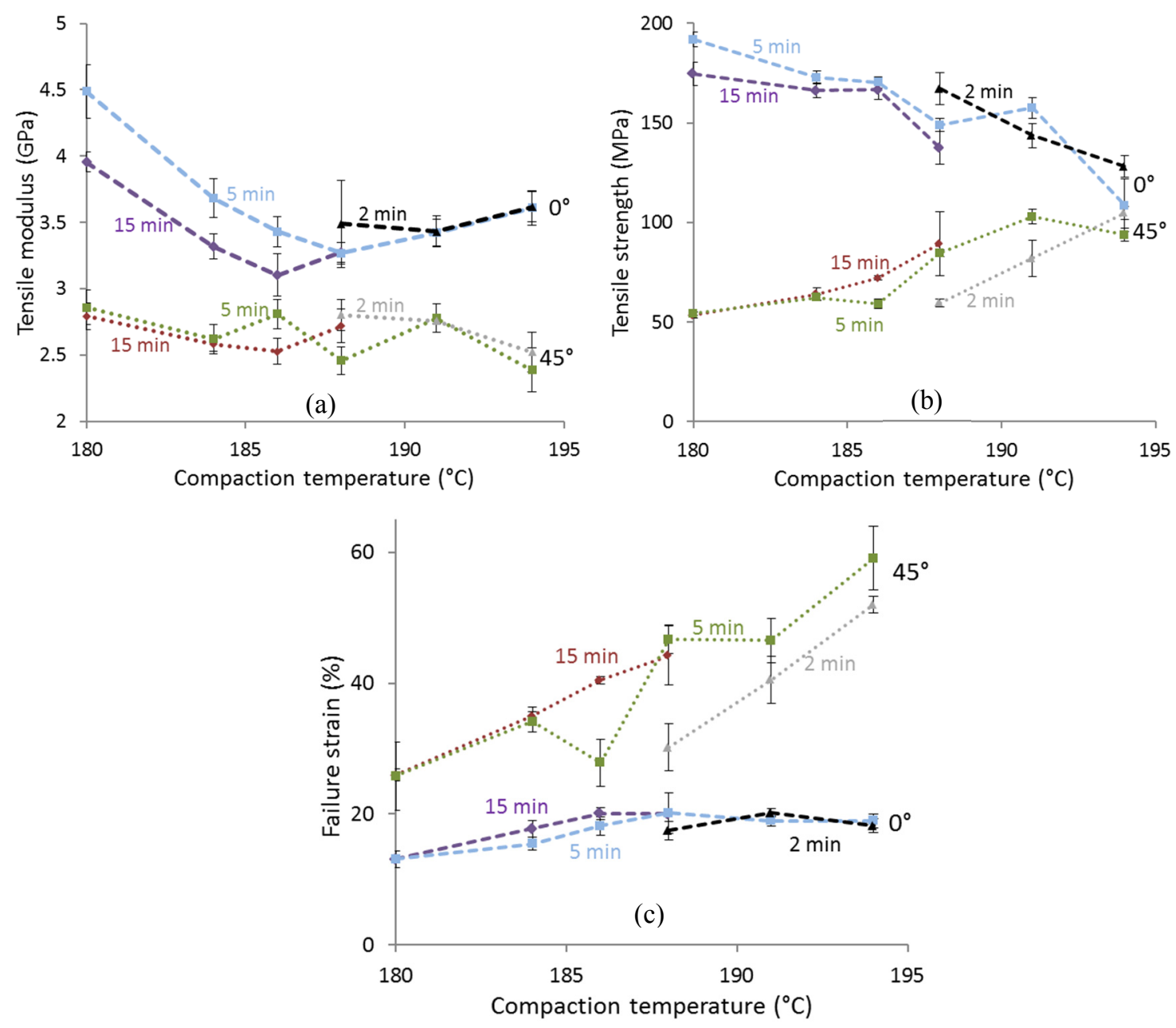

Figure 5: Tensile properties with interleaved films in $0^{\circ}$ and $45^{\circ}$ as a function of temperature and dwell time: (a) tensile modulus, (b) tensile strength, and (c) failure strain. 


\subsection{Penetration impact resistance}

Fig. 6 displays the penetration impact resistance as a function of the compaction temperature for samples with a dwell time of $5 \mathrm{~min}$, after normalisation for sample thickness. Fig. 7 shows the force-displacement diagrams for representative samples, while Fig. 8 shows the samples after impact. The samples compacted at $180^{\circ} \mathrm{C}$ without films are not plotted in Fig. 6 and 7a, as these samples could not be penetrated. Instead, they completely delaminate during impact, resulting in separated layers folding into the impact ring. An example of such a sample can be seen in Fig. 8 a.

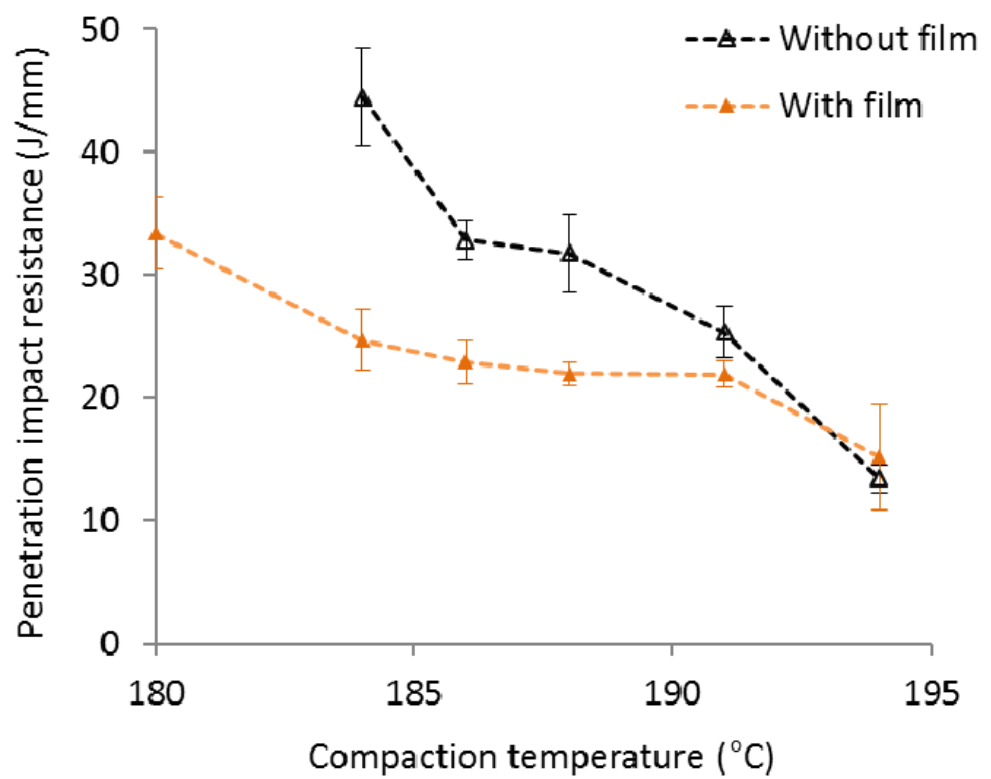

Figure 6: The penetration impact resistance as a function of compaction temperature for samples without and with films at a dwell time of 5 minutes. The samples compacted at $180^{\circ} \mathrm{C}$ without films are not shown in this figure, as they were not penetrated.

Samples with films reach a plateau in penetration impact resistance between $184^{\circ} \mathrm{C}$ and $191^{\circ} \mathrm{C}$, similar to the plateau described by Alcock et al. for co-extruded self-reinforced PP [5]. This similarity makes sense, as the outer layer of co-extruded tapes provide matrix similar to the way interleaved films do. If enough matrix is present, then a further increase in the matrix fraction will not cause a further increase in interlayer bonding, leading to the observed plateau in penetration impact resistance. Samples without films did not display this plateau, but show a monotonic decrease of the penetration impact resistance with increasing compaction temperature. This illustrates the difficulty of obtaining enough matrix material in hot compaction without interleaved films.

Above $190^{\circ} \mathrm{C}$, the molecular orientation is starting to get lost, which results in a decreased penetration impact resistance, both for samples with and without films. This is also observed in Fig. 7, which demonstrated more brittle behaviour for the samples compacted at $194^{\circ} \mathrm{C}$. Another crucial feature of these results is that both data sets seem to converge at $191^{\circ} \mathrm{C}$. At this compaction temperature or higher, the additional films do not affect the penetration impact resistance.

Fig. 8 presents the photographs of representative samples after penetration. The sample in Fig. 8a, which was compacted at $180^{\circ} \mathrm{C}$ without film, demonstrates that the interlayer 
bonding was too low. The sample was heavily deformed by the delamination of the layers and debonding of the tapes. By adding films, the interlayer bonding is improved, which hampers these mechanisms and facilitates penetration (see Fig. 8d). At $188^{\circ} \mathrm{C}$, the damage is circular (see Fig. $8 \mathrm{~b}$ and e), while it becomes smaller and more crossshaped at $194^{\circ} \mathrm{C}$ (see Fig. 8c and f). This is caused by the improved interlayer bonding, changing the dominant damage mechanism from delamination and tape debonding to tape fracture.
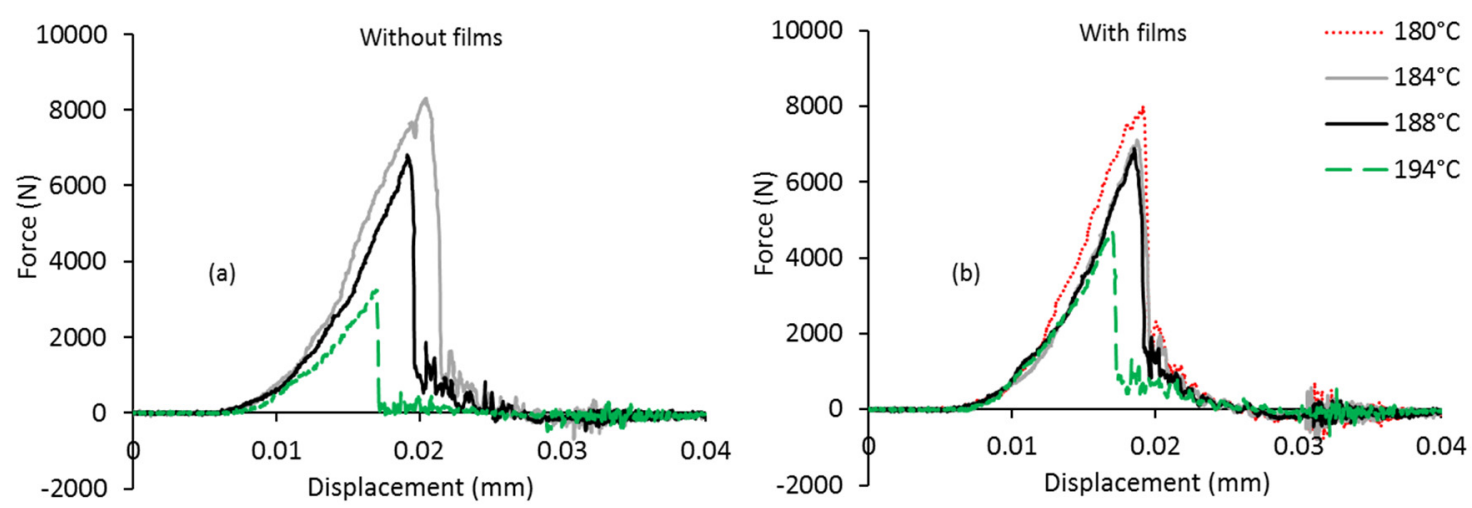

Figure 7: Force-displacement diagrams for penetration impact tests on samples (a) without, and (b) with films at a dwell time of 5 minutes. The diagrams for $186^{\circ} \mathrm{C}$ and $191^{\circ} \mathrm{C}$ were omitted for clarity.

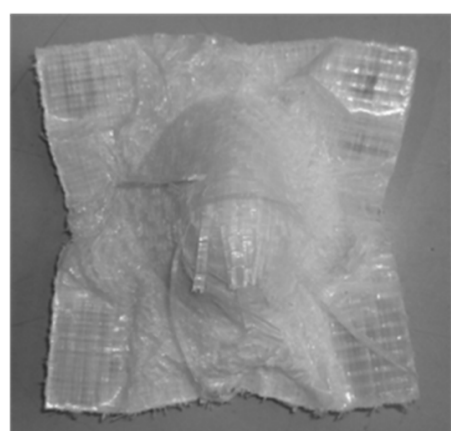

(a) $180^{\circ} \mathrm{C}$ without film

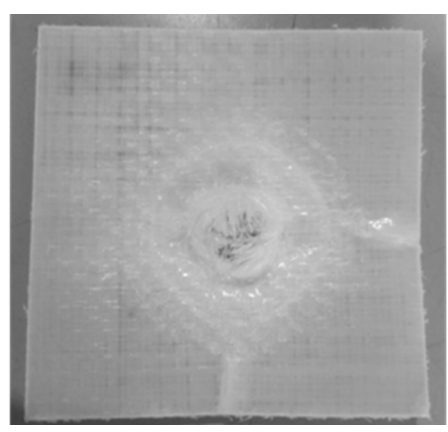

(d) $180^{\circ} \mathrm{C}$ with film

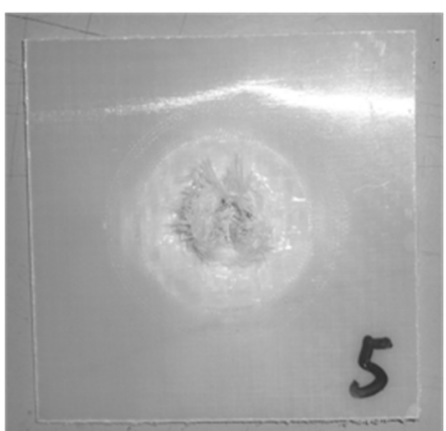

(b) $188^{\circ} \mathrm{C}$ without film

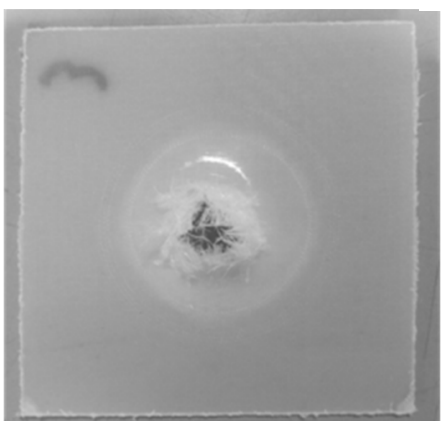

(e) $188^{\circ} \mathrm{C}$ with film

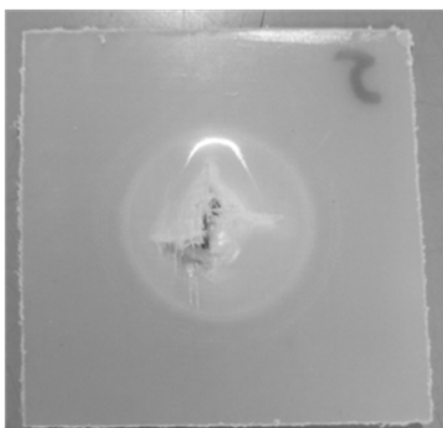

(c) $194^{\circ} \mathrm{C}$ without film

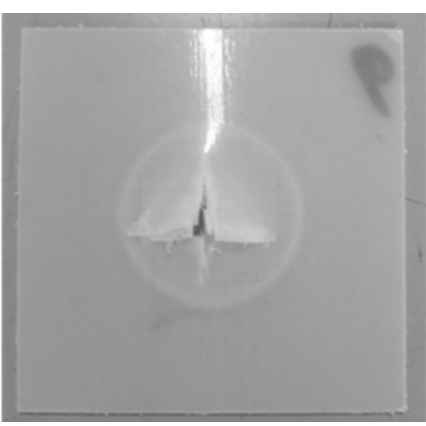

(f) $194^{\circ} \mathrm{C}$ with film

Figure 8: Photographs of samples after penetration impact tests, with indication of the compaction temperature and the presence of interleaved films.

The influence of the dwell time was investigated on samples with interleaved films and the results are summarised in Fig. 9. No clear differences are observed, meaning that dwell time does not significantly affect the penetration impact resistance for samples with interleaved films. For samples without these films, it can be expected that a higher 
dwell time, which should increase the matrix fraction and hence the interlayer bonding, will lead to lower penetration impact resistance. It is assumed that this will only become clear at longer dwell times, which were not tested in this study.

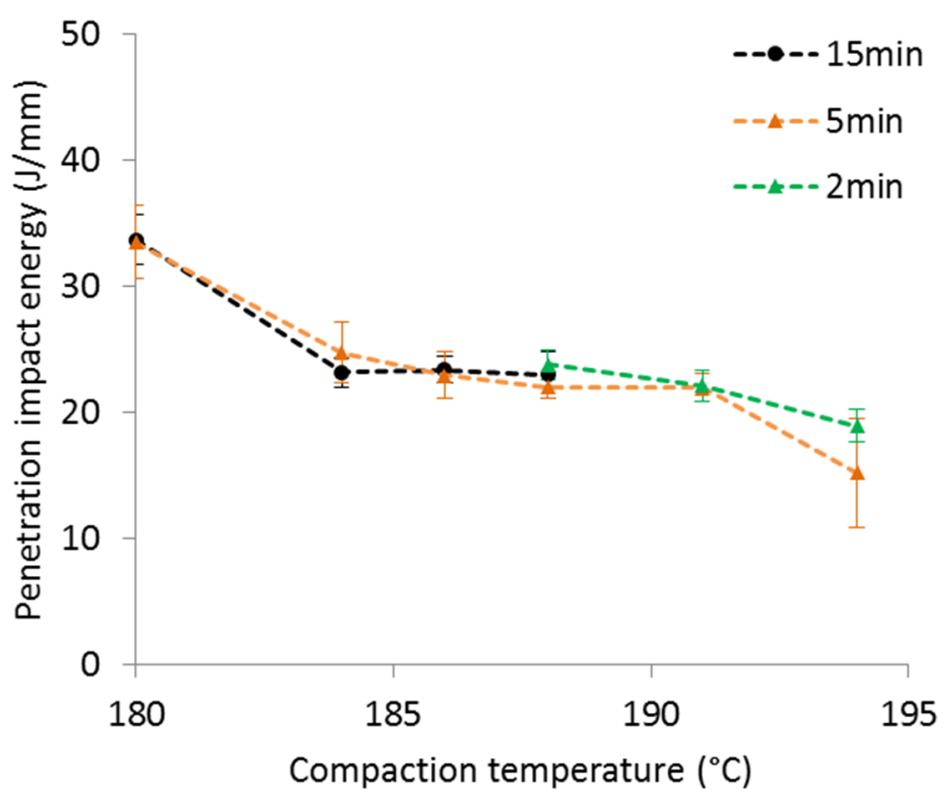

Figure 9: The influence of dwell time on the penetration impact resistance of self-reinforced PP composites with films.

\subsection{Non-penetration impact resistance}

In composites, penetration impact resistance tends to increase for poorly bonded layers, allowing the damage to spread easier and hence absorb more energy. Such composites are often insufficient for structural applications, as poor bonding leads to a decrease in other mechanical properties, such as compression strength, compression after impact and shear strength. It is useful to analyse the non-penetration impact resistance, which indicates the sensitivity of a material to impact damage. By using ultrasonic C-scans, the damaged area after an impact event can be analysed, which was not possible with the strain mapping technique used by Alcock et al. [5].

Fig. 10 presents the $\mathrm{C}$-scans for samples with films after a non-penetration impact event. To illustrate the overall quality of the samples, the C-scans of the 5J samples before impact are displayed in the top row of Fig. 10. The unimpacted samples without films displayed similar trends and are not shown here.

At $180^{\circ} \mathrm{C}$, the initial sample quality is poor. Dark grey, low quality areas are already visible prior to the impact event. As the compaction temperature is increased, the overall quality increases and the samples compacted at $184^{\circ} \mathrm{C}$ or higher all have high quality, indicated by the light grey to white colour over the whole sample area. After impact, two features arise in the C-scans: a ring on the outside, and a circular or diamond-shaped zone in the middle. The ring coincides with the clamping area and seems to fade away at higher compaction temperature. Since it is also more pronounced at the higher energy level, it is not purely related to the clamping, but also to damage introduced by the impact event. Circumferential clamping of a plate results in high 
flexural stresses, and even stress concentrations, at the clamp edges. This causes local damage, which is more severe at lower compaction temperatures and higher impact energy.

The central damage changes in size, intensity and shape. The size and intensity are mainly related to the interlaminar bonding and the energy level, while the shape is related to the damage mechanism. A diamond-shaped damage indicates tape debonding and fracture, while delaminations are less direction-dependent and cause circular damage. The circular damage is more obvious at low compaction temperatures, which is consistent with the lower bonding quality. At higher compaction temperatures, the bonding is improved and more diamond shaped pattern is observed. This is difficult to observe at $5 \mathrm{~J}$, but is clear in the $15 \mathrm{~J}$ images.

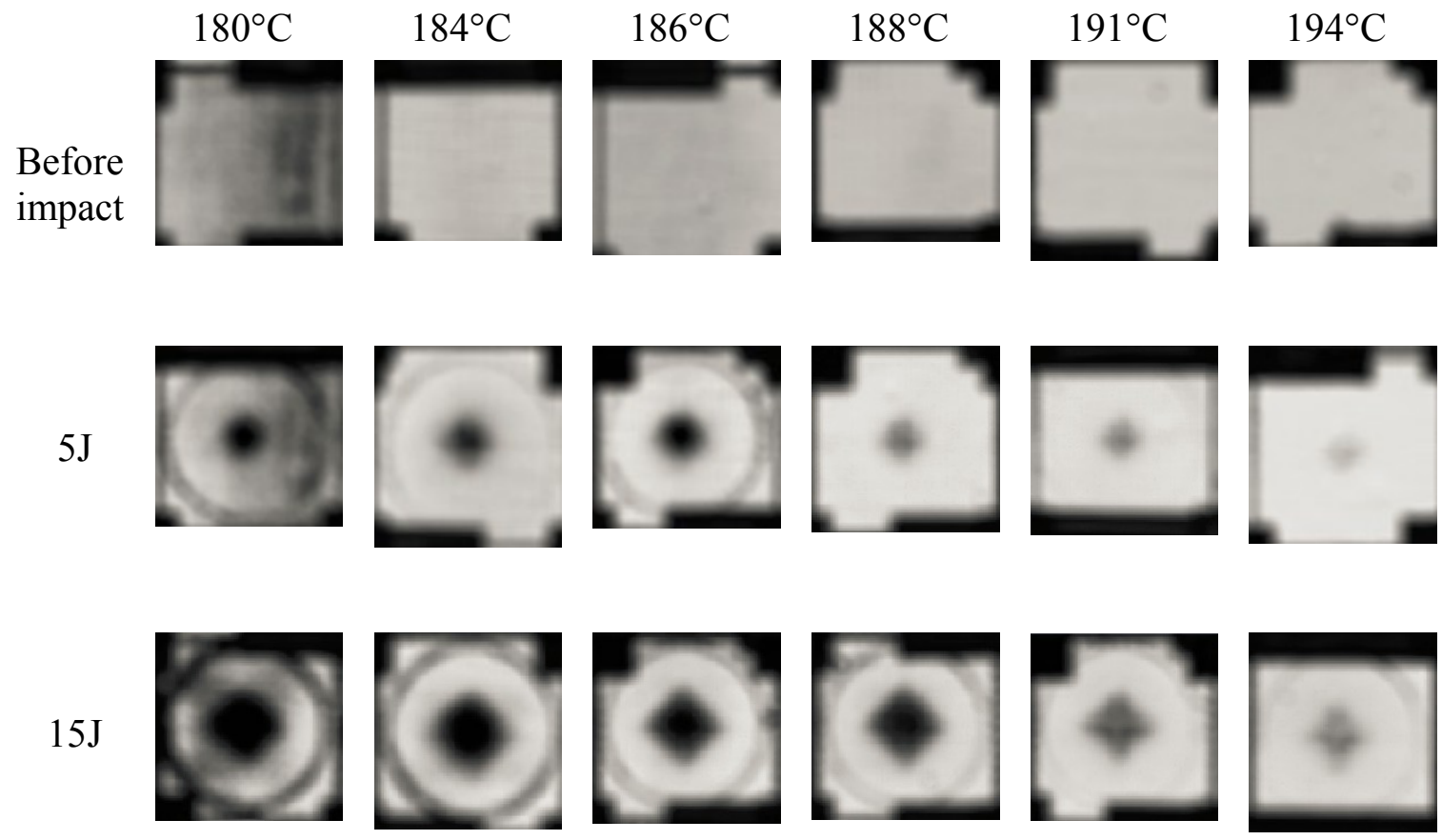

Figure 10: C-scan images of samples hot compacted at different temperatures with films. The top row displays the samples before impact, while the middle row displays the same samples after a $5 \mathrm{~J}$ impact. The bottom row shows impact samples after a $15 \mathrm{~J}$ impact. The black areas at the corners and edges are caused by the sinkers and supports and are not related to material damage.

Based on the C-scan images, the damaged area was calculated. This calculation only takes into account the central damage and neglects the outer ring. The results are summarised in Fig. 11a and b. Both figures demonstrate a strongly decreasing trend with increasing compaction temperature. In general, the interleaved films seem to slightly reduce the damaged area, although this is not the case for all configurations. 

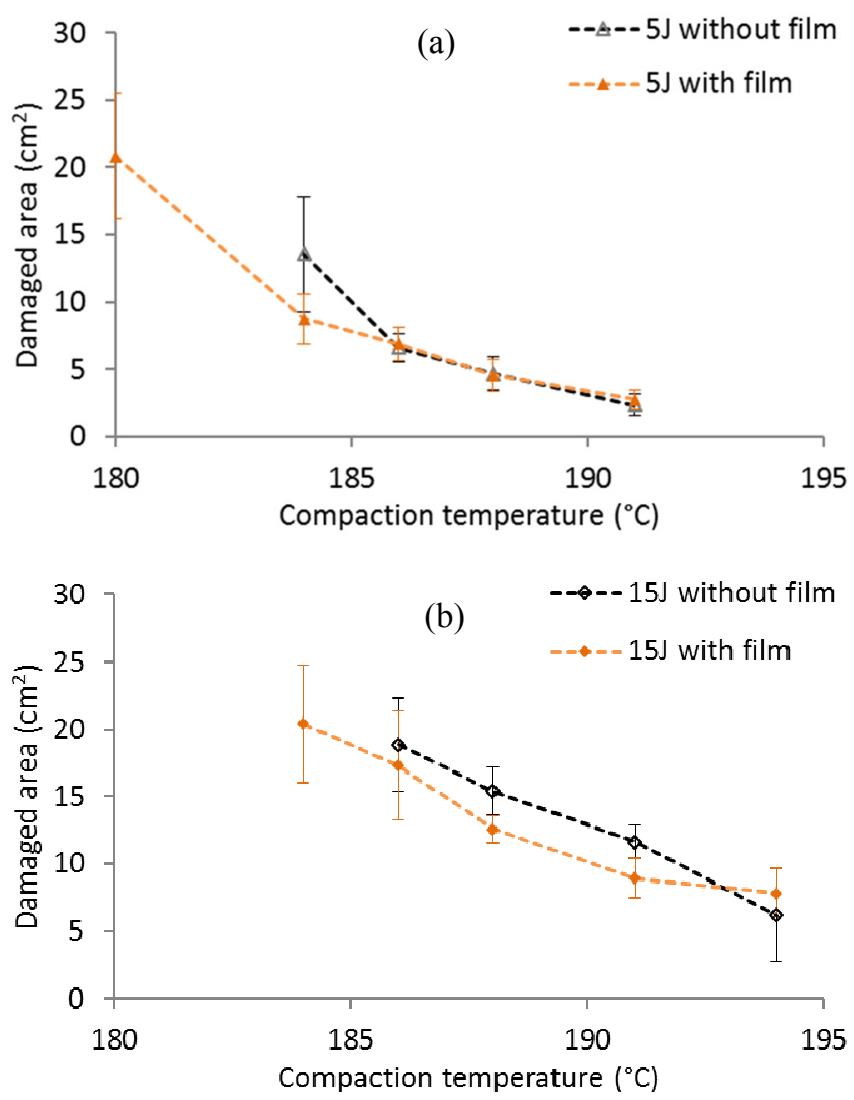

Figure 11: Damaged area as a function of compaction temperature for a dwell time of 5 min: (a) after a $5 \mathrm{~J}$ impact event, and (b) after a $15 \mathrm{~J}$ impact event. Some data points at high and low compaction temperatures were left out, as the thresholding procedure resulted in the analysed area to be either completely damaged or completely undamaged.

The dwell time has a clear influence on the damaged area, see Fig. 12. Higher dwell times allow more molecular relaxation and more matrix will be created during hot compaction. The additional matrix improves the bonding, leading to a reduction in the damaged area. The influence of dwell time was not clearly visible in most of the previously described properties, but it is clear for the damaged area results. This indicates that this test is more sensitive to the matrix fraction and the interlayer bonding than the other properties. 


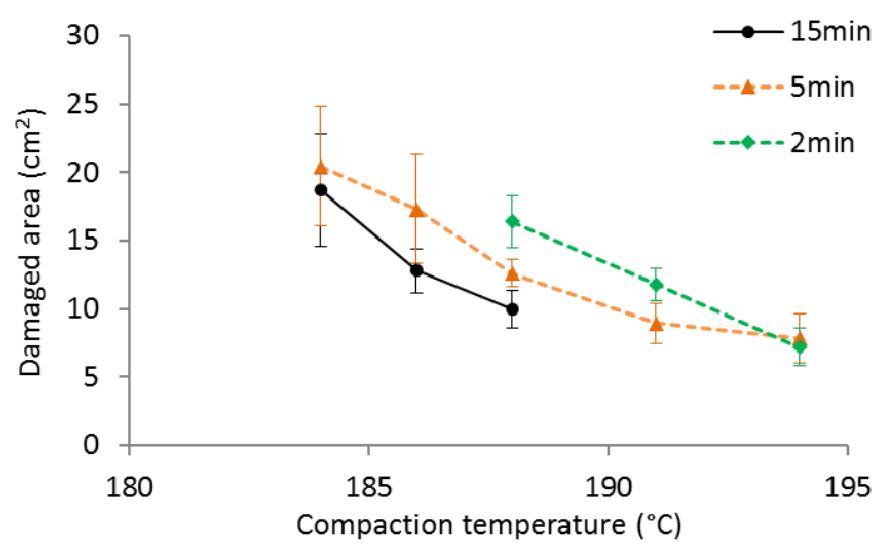

Figure 12: The influence of the dwell time on the damaged area for samples with films.

\section{Conclusion}

Three production parameters were investigated for hot compacted self-reinforced PP composites: compaction temperature, dwell time and interleaved films. Higher compaction temperature leads to more matrix creation and better interlayer bonding, but also to more molecular relaxation. The tensile properties and penetration impact resistance decreased with increasing compaction temperature, while non-penetration impact resistance increased. Interleaved films also lead to improved interlayer bonding, but without the additional molecular relaxation. This results in improved tensile strength and non-penetration impact resistance, but these improvements tend to be smaller with increased compaction temperature. Dwell time only has a small effect on the mechanical performance of hot compacted self-reinforced PP composites.

These results show that mechanical properties of self-reinforced PP composites can be tailored to specific applications in a wide range of processing temperatures and dwell times. Future work will extend the dwell time to clarify its importance and assess the influence of the compaction pressure.

\section{Acknowledgments}

The authors thank the Agency for Innovation by Science and Technology in Flanders (IWT) for the grant of Y. Swolfs. I. Verpoest holds the Toray Chair in Composite Materials at KU Leuven.

\section{References}

[1] Capiati NJ, Porter RS. The concept of one polymer composites modelled with high density polyethylene. Journal of Materials Science. 1975;10(10):1671-7.

[2] Hine PJ, Ward IM, Olley RH, Bassett DC. The hot compaction of high modulus melt-spun polyethylene fibers. Journal of Materials Science. 1993;28(2):316-24.

[3] Alcock B, Cabrera N, Barkoula N, Spoelstra A, Loos J, Peijs T. The mechanical properties of woven tape all-polypropylene composites. Composites Part A: Applied Science and Manufacturing. 2007;38(1):147-61. 
[4] Alcock B, Cabrera NO, Barkoula NM, Loos J, Peijs T. Interfacial properties of highly oriented coextruded polypropylene tapes for the creation of recyclable allpolypropylene composites. Journal of Applied Polymer Science. 2007;104(1):118-29.

[5] Alcock B, Cabrera NO, Barkoula NM, Peijs T. Low velocity impact performance of recyclable all-polypropylene composites. Composites Science and Technology. 2006;66(11-12):1724-37.

[6] Cabrera N, Alcock B, Loos J, Peijs T. Processing of all-polypropylene composites for ultimate recyclability. Proceedings of the Institution of Mechanical Engineers Part L-Journal of Materials-Design and Applications. 2004;218(L2):145-55.

[7] Hine PJ, Bonner M, Brew B, Ward IM. Hot compacted polypropylene sheet. Plastics Rubber and Composites Processing and Applications. 1998;27(4):167-71.

[8] Teckoe J, Olley RH, Bassett DC, Hine PJ, Ward IM. The morphology of woven polypropylene tapes compacted at temperatures above and below optimum. Journal of Materials Science. 1999;34(9):2065-73.

[9] Hine PJ, Ward IM, Teckoe J. The hot compaction of woven polypropylene tapes. Journal of Materials Science. 1998;33(11):2725-33.

[10] Kmetty Á, Bárány T, Karger-Kocsis J. Injection moulded all-polypropylene composites composed of polypropylene fibre and polypropylene based thermoplastic elastomer. Composites Science and Technology. 2012;73(0):72-80.

[11] Huang HX. Self-reinforcement of polypropylene by flow-induced crystallization during continuous extrusion. Journal of Applied Polymer Science. 1998;67(12):2111-8.

[12] Ward IM, Hine PJ. The science and technology of hot compaction. Polymer. 2004;45(5):1413-27.

[13] Alcock B, Peijs T. Technology and development of self-reinforced polymer composites. In: Abe A, Kausch HH, Moller M, Pasch H, editors. Polymer composites polyolefin fractionation - polymeric peptidomimetics - collagens. Berlin: SpringerVerlag; 2013. p. 1-76.

[14] Karger-Kocsis J, Bárány T. Single-polymer composites (SPCs): Status and future trends. Composites Science and Technology. 2014;92(0):77-94.

[15] Gao C, Yu L, Liu H, Chen L. Development of self-reinforced polymer composites. Progress in Polymer Science. 2012;37(6):767-80.

[16] Bárány T, Izer A, Karger-Kocsis J. Impact resistance of all-polypropylene composites composed of alpha and beta modifications. Polymer Testing. 2009;28(2):176-82.

[17] Alcock B, Cabrera NO, Barkoula NM, Wang Z, Peijs T. The effect of temperature and strain rate on the impact performance of recyclable all-polypropylene composites. Composites Part B-Engineering. 2008;39(3):537-47.

[18] Aurrekoetxea J, Sarrionandia M, Mateos M, Aretxabaleta L. Repeated low energy impact behaviour of self-reinforced polypropylene composites. Polymer Testing. 2011;30(2):216-21.

[19] Swolfs Y, Crauwels L, Gorbatikh L, Verpoest I. The influence of weave architecture on the mechanical properties of self-reinforced polypropylene. Composites Part A: Applied Science and Manufacturing. 2013;53:129-36.

[20] Abraham TN, Wanjale SD, Bárány T, Karger-Kocsis J. Tensile mechanical and perforation impact behavior of all-PP composites containing random PP copolymer as matrix and stretched PP homopolymer as reinforcement: Effect of $\beta$ nucleation of the matrix. Composites Part A: Applied Science and Manufacturing. 2009;40(5):662-8. 
[21] Xuefeng AN, Shuangying JI, Tang BM, Zhang ZL, Su YX. Toughness improvement of carbon laminates by periodic interleaving thin thermoplastic films. Journal of Materials Science Letters. 2002;21(22):1763-5.

[22] Matsuda S, Hojo M, Ochiai S, Murakami A, Akimoto H, Ando M. Effect of ionomer thickness on mode I interlaminar fracture toughness for ionomer toughened CFRP. Composites Part a-Applied Science and Manufacturing. 1999;30(11):1311-9.

[23] Hine P, Olley R, Ward I. The use of interleaved films for optimising the production and properties of hot compacted, self reinforced polymer composites. Composites Science and Technology. 2008;68(6):1413-21.

[24] Swolfs Y, Crauwels L, Breda EV, Gorbatikh L, Hine P, Ward I, et al. Tensile behaviour of intralayer hybrid composites of carbon fibre and self-reinforced polypropylene. Composites Part A: Applied Science and Manufacturing. 2014;59:7884.

[25] Heim H-P, Tillmann W, Ries A, Sievers N, Rohde B, Zielke R. Visualisation of the degress of compaction of self-reinforced polypropylene composites by means of ultrasonic testing. Zeitschrift Kunststofftechnik. 2013;9(6):275-94.

[26] Pinxten W. De invloed van het visco-elastisch gedrag van vertrekt polypropyleen op het krimpgedrag van polypropyleencomposieten [Master thesis]. Leuven: KU Leuven; 2005.

[27] Schimanski T, Peijs T, Lemstra PJ, Loos J. Influence of postdrawing temperature on mechanical properties of melt-spun isotactic polypropylene. Macromolecules. 2004;37(5):1810-5.

[28] Barkoula NM, Peijs T, Schimanski T, Loos J. Processing of single polymer composites using the concept of constrained fibers. Polymer Composites. 2005;26(1):114-20.

[29] Hine PJ, Ward IM, Jordan ND, Olley RH, Bassett DC. A comparison of the hotcompaction behavior of oriented, high-modulus, polyethylene fibers and tapes. Journal of Macromolecular Science-Physics. 2001;B40(5):959-89.

[30] Hine PJ, Ward IM, El Matty MIA, Olley RH, Bassett DC. The hot compaction of 2-dimensional woven melt spun high modulus polyethylene fibres. Journal of Materials Science. 2000;35(20):5091-9.

[31] Samuels RJ. High strength elastic polypropylene. J Polym Sci Pt B-Polym Phys. 1979;17(4):535-68.

[32] Dasdemir M, Maze B, Anantharamaiah N, Pourdeyhimi B. Formation of novel thermoplastic composites using bicomponent nonwovens as a precursor. Journal of Materials Science. 2011;46(10):3269-81. 